\title{
La cultura visual en los procesos de documentación sobre cómo los jóvenes aprenden dentro y fuera de la escuela secundaria
}

\section{Resumo}

La cultura visual ha transitado desde la academia a la escuela y lo ha hecho mediante apropiaciones, transformaciones, variaciones y controversias. En este recorrido ha pasado de ampliar los artefactos que median modos de aprender -dentro y fuera de la educación de las artes visuales- a aportar un marco -epistemológico y metodológico- que permite construir modos de narrar experiencias de relación pedagógica. Tomando como punto de partida el esbozo de este trayecto, en este artículo se presenta una concepción de la cultura visual expandida vinculada a procesos de documentación y narración. Para ilustrar su sentido se han tomado evidencias del trabajo de campo que ha tenido lugar en la investigación etnográfica (IN-OUT) realizada con jóvenes de educación secundaria en torno a cómo aprenden, se expresan y relacionan dentro y fuera de la escuela. Todo ello con la finalidad de desvelar los discursos que naturalizan la mirada y conforman subjetividades y espacios para la acción.

Palabras-clave:

Cultura visual, investigación etnográfica, documentación en educación. 


\title{
Visual culture in the process of documentation of youth learning in and out of secondary school
}

\author{
FERNANDO HERNÁNDEZ-HERNÁNDEZ
}

\begin{abstract}
Visual culture has moved from academia to school through appropriations, changes, variations and disputes. On this journey visual cultures has expand the artifacts that mediate modes of learning -inside and outside visual arts education-, to provide an epistemological and methodological frame that allows building modes of narrating experiences of pedagogical relationship. Taking this trajectory as starting point, this article presents a concept of expanded visual culture linked to processes of documentation and narrative. To illustrate its meaning have taken evidences from an ethnographic research (INOUT) developed with high school youth about how they learn, express and communicate within and outside school.

The purpose of this paper is to disclose discourses that naturalize gaze experiences and shape subjectivities and spaces for action.
\end{abstract}

Keywords:

Visual culture, ethnographical research, documentation in education. 


\section{Situar la Cultura Visual en la educación}

Si bien la mente de Adamsberg era calamitosa para almacenar palabras, resultaba de una precisión extrema para lo referente a las imágenes.

Fred Vargas (2012, p.222)

Hacia la mitad de los años noventa del pasado siglo tuvieron lugar una serie de debates y cuestionamientos de las narrativas dominantes en la Educación de las Artes Visuales, bajo el influjo del debate cultural postmoderno (EFLAND, FREEDMAN, STUHR, 2003; HERNANDEZ, 2005; FREEDMAN, 2006; DUNCUM, 2009), las transformaciones en las representaciones de los sujetos infantiles y juveniles mediadas por las pedagogías culturales (STEINBERG y KINCHELOE, 2000), y el papel que los nuevos dispositivos tecnológicos tenían en la producción, distribución y almacenamiento de imágenes en las experiencias de comunicación en red (MIRZOEFF, 2003). Estos cambios y cuestionamientos hacían necesario, pensamos algunos, reflexionar sobre la orientación de la Educación de las Artes Visuales.

Al mismo tiempo emergía una corriente, que terminó por denominarse Educación de las Artes y la Cultura Visual (DUNCUM, 2009; HERNANDEZ, 2010a) que no buscaba sólo ampliar los objetos y artefactos que podían formar parte del acervo de estudio del arte en la educación, incluyendo los que forman parte de la cultura popular. Lo que se proponía no era una cuestión de 'objetos' sino de las estrategias y formas de aprender. Era una cuestión epistemológica, metodológica y política. Lo que significaba que la pregunta a responder no era 'qué es la cultura visual y qué objetos se incluyen bajo su paraguas' sino cómo favorecer el cambio de posicionamiento 
de los sujetos, y pasaran a constituirse de receptores o lectores a visualizadores y autores críticos.

El desafío consistía en quebrar los posicionamientos hegemónicos respecto a las manifestaciones y las prácticas artísticas, explorando relaciones y posibilidades de interpretación y producción que hasta ahora no habían sido consideradas por las narrativas autoexpresivas o disciplinares de la Educación Artística. Esto suponía, por ejemplo, expandir la pregunta que había sido central en la educación de la imagen (en la escuela y los museos) ¿qué ves en esta imagen? ¿qué historia cuenta esta obra? y dirigirse hacia un terreno que había sido poco explorado: ¿qué veo de mí en esta representación visual?

Este planteamiento supuso desplegar una mirada diferente hacia las artes visuales a la que suelen plantearse desde el esencialismo de la mayoría de las tradiciones de educación artística - también son esencialistas las otras disciplinas escolares, pero no es nuestro propósito debatir ahora la fundamentación del currículo escolar-, puesto que son hijas de una modernidad que trataba de fundamentar el debe ser de los individuos y de la sociedad. Desde una idea sagrada del papel de la escuela en la formación del ciudadano y de la patria. En este marco, las artes (la música, el teatro, la danza, las artes visuales) han puesto el énfasis en su valor salvador de lo esencial del ser humano (por su relación con la verdad, la belleza y el bien que plantea Kant), frente al materialismo y las formas de alienación derivadas del capitalismo primero o de los totalitarismos surgidos en el siglo pasado. Esto ha llevado a considerar las artes y la actividad de los artistas, como libres de intereses y como una especie de santos que se sacrifican en el altar del arte para redimirnos a los demás humanos. Posición que la perspectiva de la educación desde la cultura visual invitaba a cuestionar.

En lo que a mí se refiere, la cultura visual, su estudio y su vinculación con prácticas pedagógicas, ha formado parte de mi trayectoria desde que en 1997 publiqué el libro Educación y cultura visual (HERNÁNDEZ, 1997). En este tiempo he recorrido diferentes posiciones que me han permitido transitar desde una postura inicial que consideraba, como en su día señaló MITCHELL (2002), a la cultura visual como el campo de artefactos, representaciones y relatos que se investiga desde los Estudios de cultura visual. Lo que significó explorar cuestiones epistemológicas y genealógicas tal y como se refleja, por ejemplo en HERNÁNDEZ (2005) y especialmente en 
HERNÁNDEZ, (2006), que me han llevado hasta la posición actual desde donde la pongo el énfasis en los procesos relacionales que los sujetos llevan a cabo en diferentes entornos y mediante los cuales se reconocen, autorizan o resisten (HERNÁNDEZ, 2013). En este trayecto he ido posibilitando la producción de experiencias educativas que he vinculado a pedagogías de la cultura visual (HERNÁNDEZ, 2011) y que me han permitido transitar por las posibilidades y dificultades que el abordaje relacional de la cultura visual ofrece para construir otra narrativa para la educación (en la escuela, en los museos, en la universidad,...).

Lo que ahora me interesa es explorar la noción y la praxis de cultura visual como un espacio que posibilita procesos de relación. Se trata por ello de dejar de lado lo que yo había hecho hasta ahora: tomar las series y relaciones de imágenes como un resultado y pasar a tomarlas como un punto de partida para una conversación cultural en torno a dos cuestiones:

- Qué miradas culturales propician.

- Qué experiencias de subjetividad median.

Articularlo de esta manera supone aproximarse desde algunas contribuciones de los Estudios de cultura visual en la educación a lo que sería un cruce entre lo que sería una mirada cultural (visualidad) y los procesos de subjetividad (qué dice de quien mira y construye el relato visual) que se derivan. Con esta aproximación no sólo se pretende aprender a narrarse, en un ejercicio de reflexividad, sino constituir un trayecto que posibilite, desde las conversaciones, los procesos de indagación y los proyectos desarrollados, plasmar visualmente ese tejido de visualidades y subjetividades.

Esta aproximación permite además cuestionar, al menos, dos asunciones que circulan sobre la cultura visual: que no son los objetos y artefactos visuales, sino las relaciones que mantenemos con ellos y poner a debate la idea de producción como única finalidad, pues no sólo se trata de hacer con (mediante apropiaciones creativas) sino de ser con.

La cuestión no son sólo los objetos, sino cómo estos se abordan, la indagación que posibilitan y el espacio de interacción e intercambio que nos brindan en esa encrucijada entre la mirada de la realidad que construyen y la mirada cultural que los visualizadores proyectan. (HERNÁNDEZ, 2010’a, p. 11). 
Desde esta posición considero, en paralelismo a lo que he apuntado en otro lugar respecto al papel del investigador en la perspectiva basada en las artes (HERNÁNDEZ, 2008), que el visualizador es alguien que forma parte de lo que ve, que nutre las historias y no sólo las recoge, que se puede mostrar desde una subjetividad vulnerable y en crisis. Lo que se persigue no es tanto capturar la realidad, la verdad de las imágenes, como producir y desencadenar nuevos relatos, es decir, "contar una historia que permita a otros contar(se) la suya” (Hernández, 2008, p. 97). Veamos como todo esto cobra sentido en el marco de una investigación realizada con jóvenes.

\section{La cultura visual expandida en una investigación sobre cómo los jóvenes aprenden, se relacionan y comunican dentro y fuera de la escuela}

Hace dos años, y como parte de un programa de investigación sobre los modos de constituirse en sujeto que propicia la escuela secundaria, iniciamos la investigación IN-OUT: "Vivir y aprender con nuevos alfabetismos dentro y fuera de la escuela secundaria: aportaciones para reducir el abandono, la exclusión y la desafección escolar de los jóvenes" (EDU2011-24122). Mediante esta investigación tratamos de comprender, mediante una serie de estudios etnográficos de carácter presencial (ANDERSON, 1989: DENZIN, 1997; TROMAN; WALDORF, 2005) y virtual (HINE, 2000; 2005; JHONS; SHIN-GLING; HALL, 2004) cómo los jóvenes utilizan los alfabetismos múltiples para aprender, expresarse y comunicarse dentro y fuera de la escuela secundaria.

En este marco la cultura visual adquiere un nuevo sentido más allá de la historicidad de las imágenes, su interpretación o producción por parte de los visualizadores. Permite, al documentar el proceso de investigación, desvelar el tránsito que los jóvenes realizan cuando se convierten en investigadores etnográficos de su propio proceso de aprender. El papel de las imágenes, como apoyo al relato que construyen de su recorrido, les permite explorar modos de relación que de otra manera se mantendrían silenciados. Lo que expande el sentido de la cultura visual más allá de la relación con las representaciones visuales existentes y convierte a los jóvenes en actores y autores de sus propios relatos y representaciones. 
De esta manera la cultura visual se conecta con una concepción de la pedagogía cultural relacionada con prácticas sociales que configuran identidades y subjetividades. Se abre entonces la articulación de un espacio de interacción entre lo pedagógico y lo cultural en el que se entrecruzan cuestiones sociales, políticas e institucionales en la constitución de identidades y en la producción de conocimiento y saber de los jóvenes.

\section{Trazos del proyecto "Cómo nos comunicamos, expresamos y aprendemos"}

El proyecto comenzó con la elaboración de un relato autobiográfico por parte de cada investigador en torno a su experiencia de aprender dentro y fuera de la escuela secundaria. Esto permitió, como señala Condominas (1991, p.41) "exponer mis (nuestras) coordenadas personales, con el fin de que sea posible mesurar la influencia que han ejercido, sin yo saberlo, sobre los resultados que exponga. La utilidad de este paso no afecta únicamente al tipo de trabajo abordado, sino a la naturaleza misma de la etnografía". Los relatos se analizaron tematizándolos y poniéndolos en relación para comprender cómo las experiencias de los investigadores podían estar presentes en nuestra mirada hacia los jóvenes durante el trabajo de campo.

Como en proyectos anteriores (HERNÁNDEZ; PADILLA, 2011) habíamos aprendido a dudar de la manera en cómo los investigadores representamos y nos dirigimos a los jóvenes, uno de nosotros concertó un encuentro con una joven que había terminado primero de bachillerato. La finalidad, no sólo era tener su punto de vista sobre la investigación que nos proponíamos realizar, sino que nos ayudara a encontrar las palabras que nos permitieran entrar en contacto con los jóvenes y hacernos comprender. Siguiendo sus observaciones tomamos las siguientes decisiones: no separar de manera dicotómica el aprender dentro y fuera de la escuela; no hablar de múltiples alfabetismos sino de modos de comunicarse y expresarse; construir el proceso de investigación tomando las decisiones de manera compartida con los jóvenes; implicar al profesorado desde el inicio el proceso de la investigación.

Con este bagaje se han llevado a cabo 5 estudios etnográficos en otros tantos institutos ubicados en la ciudad de 
Barcelona (1), en la comarca del Barcelonés (3) y en la del Montsià (1) con otros tantos grupos (formados por jóvenes cumplen y no cumplen las expectativas de la escuela) con la finalidad de comprender los significados de los que dotan a su relación con la escuela secundaria y con el aprendizaje con alfabetismos múltiples dentro y fuera de la misma. En cada escuela hemos estado dos investigadores.

Estos estudios se han realizado de manera colaborativa con los jóvenes (HEATH, BROOKS, CLEAVER \& IRELAND, 2009). Lo que ha significado desde un primer momento no sólo compartir con ellos lo que se pretende llevar a cabo sino negociar su lugar (y el nuestro) en el proceso. Además se les ha introducido en la investigación etnográfica y a los modos de recoger las evidencias que han utilizado (diario de campo, modos de observación, prácticas de entrevista). Lo que les ha permitido abrirse a la reflexión sobre los materiales y propuestas de aprendizaje, sus reacciones ante las observaciones realizadas en clase y en otros entornos fuera de la escuela,... De la noción expandida de cultura visual que se refleja en esta investigación es de lo que doy ahora cuenta.

\section{La cultura visual como documentación de un proceso de investigación}

La cultura visual expandida tiene que ver con explorar maneras de narrar la experiencia de los sujetos que participan en procesos sociales. En el caso de la investigación que nos ocupa esta narración la realizan tanto los investigadores como los jóvenes (imágenes 1 y 2).

Imágenes 1 y 2: Los jóvenes como documenalistas de su propia investigación.
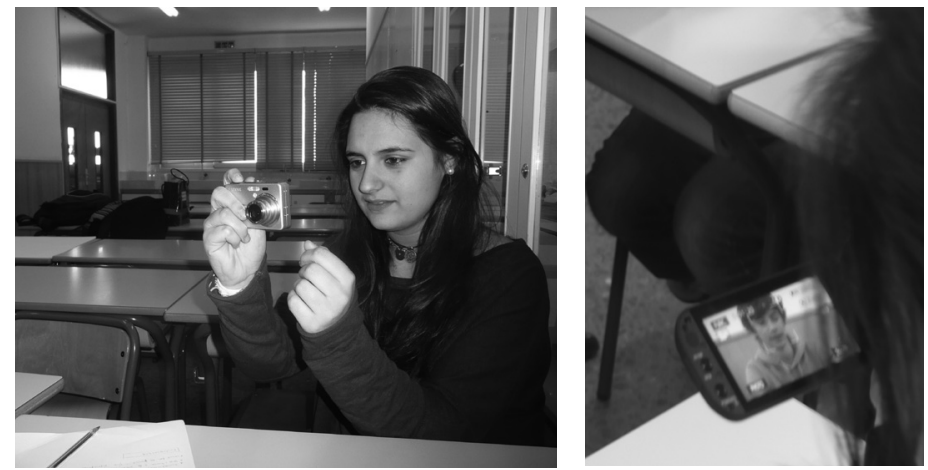
Su función es doble. Por una parte un ejercicio de autorización y por otro de visibilización de aquello que, si nos mantuviéramos solo en el relato escrito, se mantendría invisible. En buena medida se relaciona con algunas de las problemáticas que están planteando los métodos visuales (GRADY, 2008), y que requiere superar la visión descriptiva e ilustrativa del papel que juegan las imágenes en la investigación social.

Vincular la cultura visual a procesos de documentación supone, en primer lugar, abrirse a una reflexión sobre el porqué de lo que hacemos, al tiempo que narramos nuestra actuación y la de los jóvenes, desde la consideración de que cuando documentamos también aprendemos (ver imágenes 3 y 4) y generamos procesos de indagación y de extrañamiento. Lo que sucede cuando el investigador se siente atrapado en la mirada de los otros, dejándose ver cómo es visto por ellos. $\mathrm{O}$ cuando los jóvenes presentan a el profesorado y diferentes invitados su recorrido por el proyecto quebrando la posición en la que normalmente son colocados: como quienes escuchan y no -como se aprecia en esta ocasión- como quienes tienen la voz y se autorizan a hacerla pública.
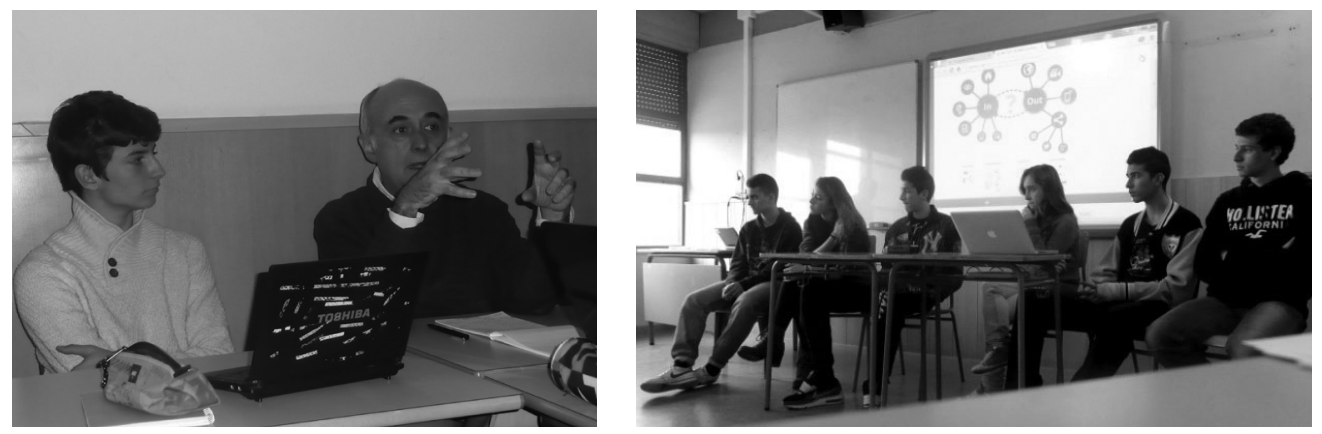

Lo que nos lleva a considerar que cultura visual, documentación y narración han de vehicularse a la reflexión. Esto significa ir más allá de la descripción y afrontar la necesidad

Imágenes 3 y 4: Modos de relación y reposicionamiento que vehiculan las imágenes. de poner en contexto las relaciones y formas de comprensión que documentamos y narramos. Lo que significa dar cuenta de lo que fundamenta de las decisiones que tomamos y las implicaciones de aquello que narramos.

Una segunda característica que emana de este caso es que documentar está vinculado a una actividad de indagación. Lo que significa que es un medio, una estrategia de hacer público 
Imágenes 5 y 6: Las huellas que va dejando el proceso de indagación. un proceso. Esto hace que siempre esté presente un Otro aquel a quien nos dirigimos, aquel a quien acompañamos- en la tarea de documentar y narrar. Compartir con otros aquello que para nosotros tiene un valor significativo supone plantearnos hasta donde estamos dispuestos a que entren a formar parte de aquello de lo que damos cuenta. Nos lleva a decidir sobre lo que queremos que sea dicho o mostrado y lo que vamos a mantener invisible. Pero también nos hace pensar sobre el modo de narrar, de manera que el Otro pueda autorizarse a interpretar aquello que le mostramos. Esto significa cuestionar la autoreferencialidad que tiene lugar cuando al narrar no tenemos en cuenta que no lo hacemos para nosotros sino para otros: quienes participaron y quienes no estuvieron allí.

Esta cuestión de estar allí es algo que nos aporta la investigación etnográfica y que nosotros tratamos de tener en cuenta en la investigación con los jóvenes. Lo que hacemos no es una obra artística de carácter conceptual que necesita un manual de instrucciones para saber de qué va. Es la narración de un proceso que se muestra de tal manera que el Otro pueda tener una experiencia próxima a la de quien estuvo allí. A modo y manera de cómo lo intentan los etnógrafos. No estamos haciendo cine experimental o vídeo arte, sino dejar rastros de la memoria de la experiencia para que las historias puedan ser contadas y desveladas (ver imágenes 5 y 6 ).
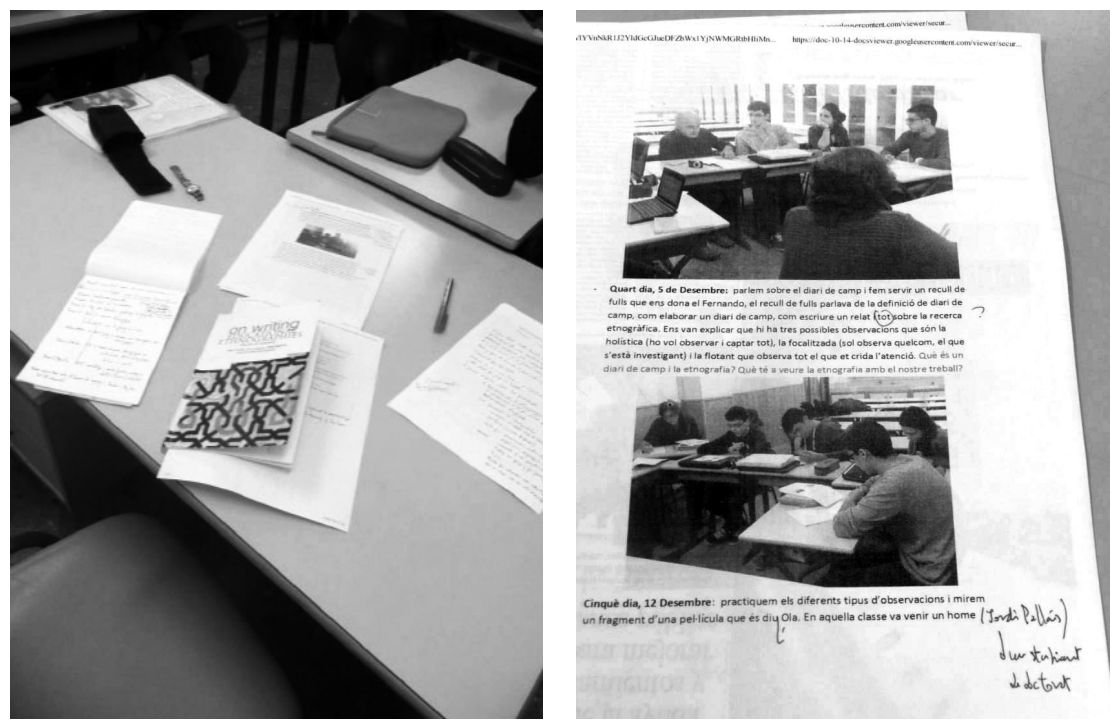
Una memoria del proceso de la investigación etnográfica, que toma como referentes las huellas y las fuentes del relato que luego se hace público. Lo que nos lleva a considerar cuál va a ser el lugar del público a quienes van dirigidas las señales de la cultura visual que se despliegan. Hemos de decidir entonces si dejarnos atrapar por la fantasía de una totalidad pedagógica (ATKINSON, 2011) y tratar de explicarlo todo o vamos a dar espacio para que cada lector o visualizador construya su propio relato. Lo que nos lleva a decidir si le colocamos en la posición de un sujeto pasivo al que hay que tomar de la mano, o asumimos que sólo nos es posible abrir una puerta para que pueda transitar y organizar su propio recorrido. Por eso habría que pensar qué claves le damos para que haga su propio tránsito y, al tiempo, que no se sienta perdido.

La tercera consideración tiene que ver con que la documentación pone de manifiesto lo que apuntaba un poema de João Guimarães Rosa: permite tener conciencia de que cuando enseñamos también aprendemos. Por eso, de lo que damos cuenta es de lo que estamos aprendiendo cuando nos mostramos y narramos visualmente. Cuando el grupo de jóvenes decidió hacer un vídeo para mostrar su trayectoria en la investigación (http://www.youtube.com/ watch?v=O86j5ElerRo), desvelaron una visión del proceso que les colocaba como referentes de la investigación. Pero además nos permitió aprender de sus descubrimientos y decisiones. Colocó el papel de los investigadores en una posición de acompañamiento, como visualizadores que se autorizan, junto a los estudiantes -aunque desde un lugar diferente- a decir lo que aprendíamos sobre lo que nos mostraban. Lo que incluía compartir las dudas que nos planteaban algunas decisiones que habían tomado: lo que vemos y no vemos, nosotros que también habíamos tenido una experiencia de ese proceso, en lo que nos mostraban.

\section{Modos de documentar y narrar}

Situados algunos de los sentidos que puede adoptar la cultura visual cuando se vincula a la documentación y la narración de las relaciones que tienen lugar en un proceso de investigación con jóvenes, paso a dar cuenta de algunas de sus funciones. Entiendo este término no en su sentido de utilidad, sino asociado al propósito al que se vincula la tarea de indagación. Lo que no quiere decir que estas finalidades estén siempre explicitadas, y 
menos las ideas que las fundamentan. De aquí la importancia de reflexionar sobre ellas como ya comencé a hacerlo en otro lugar (HERNANDEZ, 2012) y que ahora recupero para ilustrarlo con aportaciones del proyecto IN-OUT.

\section{Documentar y narrar para ilustrar}

Es una modalidad necesaria, porque trata de restituir la ocultación y la desaparición del sujeto en las instituciones educativas como la escuela o la universidad. Su función va desde publicitar a compartir. El énfasis se pone en dar cuenta, a modo de reportaje, de momentos, escenas o circunstancias de una actividad o un proyecto. Se piensa, desde una perspectiva de relación con los documentos (visuales y escritos), que las imágenes y los textos hablan por sí mismos ya que señalan algo importante que se ha de percibir de manera naturalizada. Actúa como reclamo e incluso como publicidad de quien la lleva a cabo. Pero deja zonas de sombras y no tiene en cuenta otras posibilidades de mostrar. Quizá por falta de reflexión sobre las implicaciones educativas y políticas de la documentación. Permite mostrar lo que sucede ante nosotros, pero tiene el peligro de ocultar lo que no puede ser visto, desde la mirada hegemónica de quien documenta. Implica una normalización de la mirada. Veamos un ejemplo de la investigación IN-OUT (imagen 7).

Imagen 7: El proceso de construir un prezzi para presentar el trayecto del grupo.

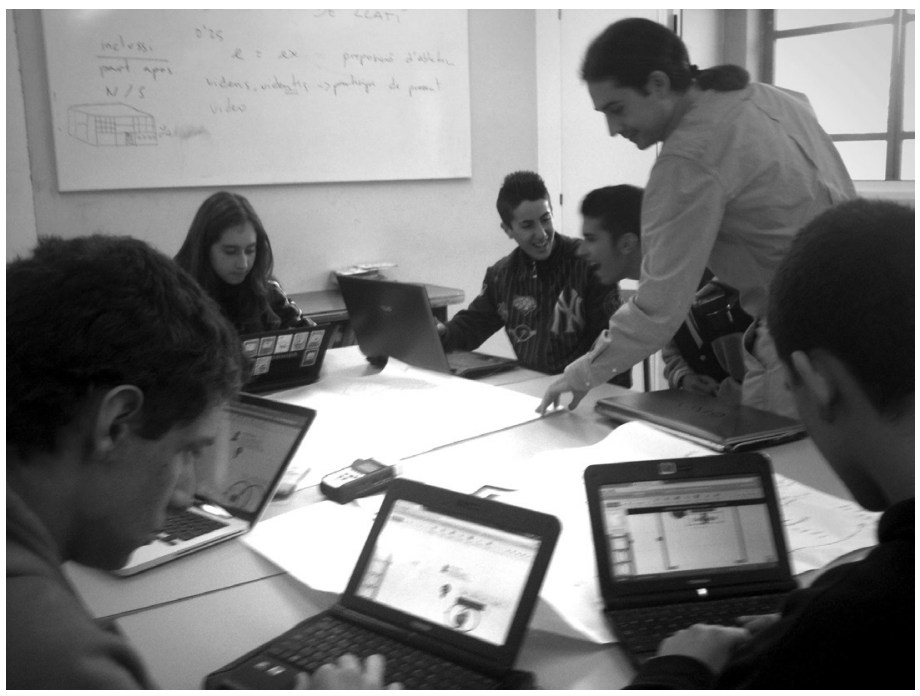


La ilustración nos muestra un grupo de estudiantes frente a sus ordenadores y hojas en las que se supone que, con la ayuda de uno de los investigadores, están señalando cómo afrontar una de las tareas de la investigación: dar cuenta mediante un prezzi de su trayectoria. La otra investigadora es la que hace la fotografía. Nos da idea de la actividad del grupo, de su aprendizaje compartido. Pero no sabemos de las tensiones, las dudas, las resistencias que se encuentran en el contenido y los límites de la instantánea. Esta es la situación que nos interesa destacar: lo que se muestra: un momento de la investigación; lo que no se ve: las dificultades del grupo para afrontar el propósito al que se les había invitado. La cultura visual expandida muestra tanto como interroga y dejar ver también lo que cuestiona.

\section{Documentar y narrar para visibilizar aquello que de otra manera se mantendría oculto}

La cultura visual en la documentación también se puede acompañar de una voluntad deliberada de mostrar no sólo lo que se hace, sino lo que de otra manera se mantendría invisible. Para ello se pone especial énfasis en las formas visuales de documentar. Se piensa en los dispositivos visuales y sus posibilidades para mostrar aspectos que las narraciones hegemónicas suelen mantener ocultas: las relaciones entre los cuerpos, los pequeños gestos, lo que ocurre en el fuera de campo, los vacíos, las posiciones silenciadas... En cierta manera se pretende prestar atención a los detalles, a lo que pasa desapercibido, y amplificarlo como lugares para la observación y la reflexión. En esta tendencia se produce una actuación deliberada que indaga en las formas de narrar y dar cuenta de los procesos formativos. Se proyecta desde una posición político-pedagógica que no sólo pretende ilustrar, sino hacerlo con sentido. Esto sucede por ejemplo, con el papel de los cuerpos y de la corporeidad del aprendizaje y la indagación (imagen 8).

Prestar atención a los detalles de aquello que parece como imperceptible. A los gestos. A una mano que sostiene el bolígrafo sobre las notas de campo que el joven va recogiendo como parte de su aprendizaje etnográfico. Se busca provocar la atención hacia el fuera de campo. Se pretende extrañar la mirada reclamando la atención sobre aquello que queda en los márgenes. Hay un riesgo en la elección y relevancia (o no)

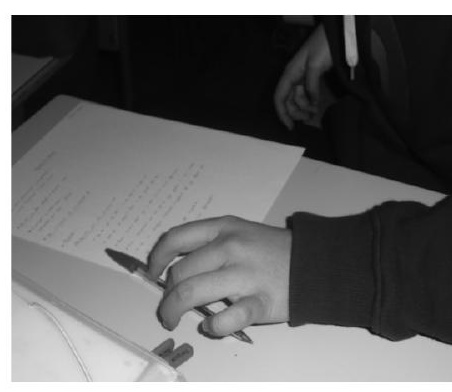

Imagen 8: Gestos del proceso de observar y narrar. 
de los detalles, pero por eso supone un desafío a afinar la mirada y su sentido. Desde aquí surge el camino de la indagación y la investigación. Hago esta distinción de la mano de EISNER (1998), quien señala que "indagación es un concepto límite entre investigación y evaluación" (p.2o), que se dirige no sólo "hacia aquellos aspectos del mundo 'de afuera', sino que también se dirige a los objetos y hechos que somos capaces de crear" (p. 40).

\section{Documentar y narrar para formarse}

No es esta una finalidad exclusiva de un modo de documentación, pero sí que es un énfasis que no siempre se suele tener en cuenta. Si bien el proceso de documentación se puede llevar a cabo para ilustrar y visibilizar, considero que toda actividad de documentación ha de educar a quienes la realicen, les ha de permitir mirarse y pensarse y a la vez dar espacio a que otros se miren y se piensen. En este sentido, la cultura visual como documentación no es una mera acción da dar cuenta de, sino un medio para que quienes documentan y compartan sus narraciones se formen (imagen 9 ).

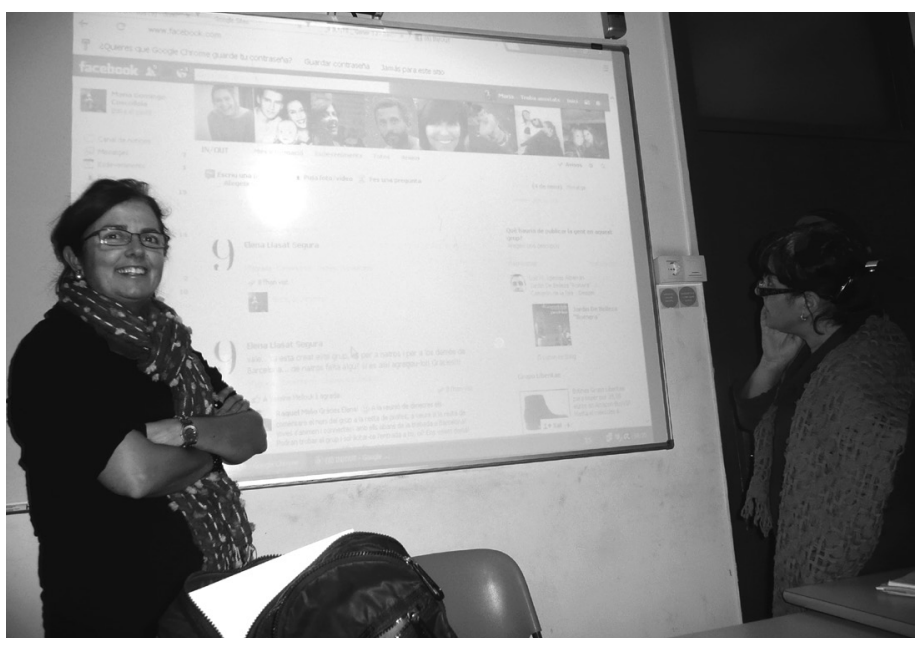

La pantalla refleja el espacio en el que se compartía la investigación. Aparecen fotos de la actividad del grupo, pero también los cuerpos de una de las investigadoras que sonríe y de la profesora que nos acompañaba en las sesiones que mira atenta la pantalla. Los adultos ante el grupo, la pantalla como foco de las miradas. Aspectos todos de la relación que 
sostenía los encuentros y sobre los cuales los jóvenes iban configurando su investigación. Quien hace la foto es el otro investigador. Muestra cómo nos colocamos ante los jóvenes; desde la complicidad y la búsqueda, desde el acompañamiento y el desafío de recorrer un camino poco transitado.

Esto significa tomar los focos, procesos y modos de representación como espacios de diálogo para indagar sobre la mirada que se proyecta sobre las prácticas educativas y las relaciones pedagógicas. Lo que hace que la cultura visual como documentación no sea un fin en sí mismo, sino un medio para conversar, reflexionar y expandir los sentidos de lo que ocurre en las aulas. Que invite a repensar(se) y cambiar de lugar. Lo que es una manera de aprender. Dónde estamos, qué dicen nuestros cuerpos, qué muestra lo que no se ve. Por eso, si narramos y documentamos es para formarnos. El relato que hora mostramos es desde uno de los investigadores. Frente a ello se abre la posibilidad de narrarse de manera conjunta, posibilitando, como dice Alfred Porres (2012), que el yo se convierta en un nosotros. Lo que replantea la relación pedagógica y el sentido de enseñar, aprender e indagar. La cultura visual aparece como camino para formarse adquiriendo otra mirada: para ir más allá de lo que pasa, de lo que se ve y apuntar hacia lo que nos pasa, a cómo nos vemos y nos ven.

\section{Documentar y narrar para investigar}

Esta modalidad pone el foco en el proceso de indagación que acompaña la toma de decisiones que organiza los procesos, actividades y resultados de la documentación. Aquí desvelar adquiere un nuevo sentido, en la medida en que posibilita relaciones, permite viajar a otros referentes y experiencias. En cierta forma, desde esta posición la documentación dialoga con propuestas como la investigación educativa basada en las artes, o con aquellas metodologías de indagación que toman las imágenes y las narrativas visuales como base para dar cuenta (documentar así se convierte en un proceso de investigación) de los interrogantes, desafíos, relaciones que se derivan de las miradas narradas en torno a las relaciones pedagógicas y los procesos que tienen lugar en el aula y la escuela como escenarios posibilitadores del cambio (imágenes 10 y 11).

Para poder documentar -como para investigar- necesitamos generar evidencias. Y a partir de ellas nos preguntamos qué y cómo vamos a narrarlo. Las evidencias pueden ser imágenes, relatos, reflexiones y textos. La distribución de los estudiantes
Imágenes 10 y $11:$ Modos de aprender a indagar.
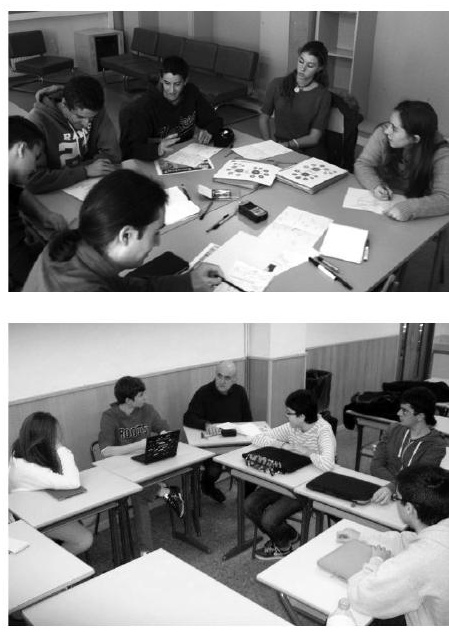
junto a uno de los investigadores se convierte en el lugar donde las evidencias se generan y comparten. Unas evidencias que hablan del lugar que se ocupa y los modos de relación, de espacios para la autoría y la escucha; de miradas y silencios; de tareas compartidas. De un proceso de grupo en suma que se fue constituyendo y que permitió aprender a indagar desde dentro de escuela secundaria. Quebrando con ello sus espacios y modos tradicionales de aprender e investigar.

\section{La cultura visual como praxis investigadora}

Documentar y narrar vinculándolo a una noción expandida de la cultura visual es un modo de ensayar otras miradas y formas de indagación desde una posición de extrañamiento o descolocación. Cuando narramos y documentamos no lo hacemos como parte de un ejercicio celebratorio sino como una forma de ponernos en tensión y salir de nuestra zona de conforto. Permitiendo que los otros entren en una red que no se acaba en nuestro grupo-clase, en un proyecto artístico, en la intervención en un museo, o en la investigación que realizamos junto a los jóvenes. Lo que pretendemos es extender a otros, generar formas de compartir que posibiliten nuevas complicidades y relaciones.

Pero no estamos solamente ante un ejercicio de visibilización, ni a un modo de utilizar las imágenes en la investigación educativa. No podemos perder de vista que la cultura visual vinculada a la documentación y la narración tienen un propósito político, en la medida en que la autoría de los sujetos participantes y su reconocimiento se convierten en una práctica de ciudadanía.

En este sentido narramos y documentamos para que las cosas, los modos de relación cambien y se transformen. Y hacerlo a partir de la narración de la memoria de lo vivido, de la reflexión que nos posibilita y el ensayo de otras formas de acción. Lo que abre un camino para pensar y ensayar sobre una perspectiva expandida de la cultura visual.

\section{Referências}

ANDERSON, Gary. L. Critical ethnography in education: Origins, current status, and new directions. Review of Educational Research, vol. 59, p. 249-270, 1989.

ATKINSON, Dennis. Art, Equality and Learning. Pedagogies Against the State. Rotterdam, Holanda: Sense, 2011. 
CONDOMINAS, Georges. Lo exótico es cotidiano. MadridGijón: Júcar Universidad, 1991 (1965).

DENZIN, Norman. Interpretative Ethnography. Thousand Oaks, CA.: Sage, 1997.

DUNCUM, Paul. Visual Culture in Art Education, Circa 2009. Visual Arts Research, Vol.35, p. 64-75, 2009.

EFLAND, Arthur; FREEDMAN, Kerry; STUHR, Patricia. La educación en el arte postmoderno. Barcelona: Paidós, 2003 (1996).

EISNER, Elliot. El ojo ilustrado. Indagación cualitativa y mejora de la práctica educativa. Barcelona: Paidós. 1998 (1991).

FREEDMAN, Kerry. Enseñar la cultura visual. Currículum, estética y la vida social del arte. Barcelona, Octaedro, 2006 (2003).

GRADY, John. Visual Research at the Crossroads. Forum: Qualitative Social Research, 9 (3), 2008. Se puede bajar de: http://www.qualitativeresearch.net/index.php/fqs/article/view/1173

HEATH, Sue; BROOKS, Rachel; CLEAVER, Elizabeth; IRELAND, Eleanor. Researching Young People's Lives. London: Sage, 2009.

HERNÁNDEZ, Fernando. Educación y cultura visual. Morón de la frontera, Sevilla: Publicaciones M.C.E.P., 1997.

De qué hablamos cuando hablamos de cultura visual? Educação e Realidade, 30(2), 9-34, 2005.

Elementos para una génesis de un campo de estudio de las prácticas culturales de la mirada y la representación. Visualidades (Goiás, Brasil), 4 (1 e 2 ), p. 13-64, 2006.

La investigación basada en las artes. Propuestas para repensar la investigación en educación. Educatio Siglo XXI, vol. 26, p.85-118, 2008.

Espigador@s de la cultura visual. Barcelona: Octaedro, 2010a.

A cultura visual como um convite à deslocalização do olhar e ao reposicionamento do sujeito. In Raimundo MARTINS; Irene TOURINHO (Orgs.) Educação da cultura visual. Conceitos e contextos. Santa Maria, Brasil: Editora da Universidade Federal de Santa Maria, p. 31-49, 2011.

Documentar y narrar la relación pedagógica en la universidad como proceso de formación e investigación. Conferencia en $(\mathrm{Re})$ pensar la innovación en la universidad desde la indagación narrativa. II Jornadas sobre la relación pedagógica en la universidad. Cursos de Verano, EHU/UPV-Donostia-San Sebastián - 21 y 22 de junio 2012. 
Transitar y aprender dentro y fuera de la escuela: La relación de los jóvenes con la cultura visual como espacio de posibilidad y autoría. In: Imanol AGUIRRE; Lander CALVELHE (coords.). Investigar con jóvenes: ¿Qué sabemos de los jóvenes como productores de Cultura Visual? UPN: Pamplona, p.83-92, 2013.

HERNÂNDEZ, Fernando; PADILLA, Paulo (2011). De investigador sobre jóvenes a investigar con jóvenes: relato de un proceso. I Jornadas "Investigar con los jóvenes: cuestiones temáticas, metodológicas, éticas y educativas. Barcelona, 27 y 28 de enero, 2011. Se puede bajar de http://fint. doe.d5.ub.es/seminaris/jornadesjoves/docs/Fernando_ Hernandez_y_Paulo_Padilla_Petry.pdf

HINE, Christine. Virtual Ethnography. London. Sage, 2000. (ed.) Virtual Methods. Issues in Social Research on the Internet. Oxford, New York: Berg, 2005.

JHONS, Marks; SHIN-LING, Sarina Che; HALL, G. Jon (2004 ). Online Social Research: Methods, Issues, and Ethics. New York: Peter Lang Publishers, 2004.

MITCHELL, W. J. T. Showing seeing: a critique of visual culture. Journal of Visual Culture, n. 2, jun, p. 165-181, 2002.

MIRZOEFF, Nicholas. Una introducción a la cultura visual. Barcelona: Paidós, 2003 (1999).

PORRES, Alfred. Relaciones pedagógicas en torno a la cultura visual de los jóvenes. Barcelona: Octaedro, 2012.

STEINBERG, Shirley; KINCHELOE, Joe (comps.) Cultura infantil y multinacionales. Madrid: Morata, 2000.

TROMAN, Geoff ; JEFFREY, Bob; WALFORD, Geoffrey. Methodological issues and practices in ethnography. Studies in educational ethnography. Amsterdam: Elsevier JAI, 2005.

VARGAS, Fred. El ejército furioso. Tres Cantos, Madrid: Santillana Ediciones, 2012.

NOTAS

1. El contenido de este trabajo está relacionado con la investigación "Vivir y aprender con nuevos alfabetismos dentro y fuera de la escuela secundaria: aportaciones para reducir el abandono, la exclusión y la desafección escolar de los jóvenes" Ministerio de Economía y Competitivad, España (EDU2o1124122).

Recebido em: 07/10/2013

Aceito em: 08/ 11/2013 


\section{FERNANDO HERNÁNDEZ-HERNÁNDEZ}

fdohernandez@ub.edu

Profesor de la Sección de Pedagogías culturales. Facultad de Bellas

Artes. Universidad de Barcelona. Director de los cursos de máster,

Estudios y proyectos de cultura visual (2001-2010) y Artes visuales y

Educación: un enfoque construccionista (2008-2010 y 2013...).

Coordinador del programa de doctorado Artes Visuales y Educación

(2000-2010) y de los estudios de doctorado Artes y Educación (2010,..

actualidad).

Desde 1995 miembro del grupo de investigación consolidado ESBRINA (Subjetividades y entornos de aprendizaje contemporáneos)

(http://www.ub.edu/esbrina) .

Desde 2007 coordinador del grupo de Innovación docente consolidado Indaga-t (http://fint.doe.d5.ub.es/indagat-web/) 